\title{
The effects of blog-mediated peer feedback on learners' motivation, collaboration, and course satisfaction in a second language writing course
}

\author{
Haisen Zhang \\ University of International Business and Economics, China \\ Wei Song \\ Renmin University of China, China \\ Suping Shen \\ University of International Business and Economics, China \\ Ronghuai Huang \\ Beijing Normal University, China
}

This paper reported on a study of using blogs as out-of-class assignments for the development of learners' writing competence. There were 36 students of English majors from an intact second language (L2) writing class participating in this study. A mixed method design was employed to obtain both quantitative and qualitative data. The results showed that blog-based peer feedback had a statistically significant positive correlation with learners' motivation, collaboration, and course satisfaction. The findings also revealed that the feedback was conducive to learners' self-reflection and self-confidence in L2 writing and could give rise to an enhanced L2 writing experience. The study concludes that group collaborative writing via blogging can not only encourage collaboration and self-reflection but also engage learners in noticing and co-construction of knowledge. Pedagogical implications and challenges are addressed and suggestions for future research are advanced.

\section{Introduction}

The use of weblogs, more commonly known as blogs, for social communication has been growing in popularity in recent years across the globe. The number of blog users is increasing at an exponential rate each year. Take the case of China. By the end of December 2011, the total number of blog users had climbed to 319 million, an increase of $8.2 \%$ for the same time period in 2010 (Tencent IT, 2012). The active users of micro-blogs arrived at 254 million in 2011, an increase of 150.7\% over 2010 (NetEase Tech, 2012). Chinese netizens are taking advantage of this novel form of communication to enjoy freedom of speech, to a larger extent, and blogs have become a crucially important avenue for the netizens to express their own views about personal interests, politics, and social issues. The same phenomenal growth of blogging can also be seen elsewhere. For instance, in the United States, an estimated number of blog readers reached 122.6 million in 2011, with a 2.5\% increase over the previous year (Reese, 2012). In South Korea, most of the Internet users (89.7\%) were social networking service (SNS) users, and more than $70 \%$ of these SNS users used blogs in 2011 , which accounted for $84.0 \%$ of the respondents surveyed (Korea Internet \& Security Agency, 2012). Obviously blogging has, at least to some extent, become part of social life for people in the digital era, without the demarcation of physical boundaries, social ideologies, race, and complexion.

In the educational sphere blogs have been explored for promoting teaching and learning (Brescia \& Miller, 2006; Ellison \& Wu, 2008). Kim (2008) found that blogs are advantageous over traditional computer-mediated communication (CMC) applications in terms of their affordances of interactivity, openness, visualization, and decentralization. A vast multitude of other studies (e.g., Churchill, 2009; Glogoff, 2007; Halic, Lee, Paulus \& Spence, 2010; Huck, 2007; Kang, Bonk, \& Kim, 2011; Yang, 2009; Williams \& Jacobs, 2004) have also acknowledged the educational advantages of integrating such a social media tool into the curriculum. For instance Makri and Kynigos (2007) investigated blogs applied in a graduate course. Their findings reveal that blogs can encourage reflection and interaction. The findings 
have been echoed by a number of other researchers. Williams and Jacobs (2004) also concluded that "blogs have the potential, at least, to be a truly transformational technology in that they provide students with a high level of autonomy while simultaneously providing opportunity for greater interaction with peers” (p. 145). The findings of Top's (2012) study “approved blogging as social media for learning about [learners themselves] and developing interactive connections with others" (p. 28). In her qualitative study of the educational affordances of blogs, Robertson (2011) found that "the blogs enabled students to express their emotional experiences of learning and to exchange social and cognitive support with their peers” (p. 1643). Thus it can be seen that blogs are of great value to enhance teaching and learning (Chu, Chan, \& Tiwari, 2012).

In language learning and teaching, previous research demonstrated that blogging can promote interaction (Ducate \& Lomicka, 2005; Miceli, Murray, \& Kennedy, 2010; Trajtemberg \& Yiakoumetti, 2011). Also, it can lend support to L2 learning in terms of enabling students to learn autonomously and collaboratively (Amir, Ismail, \& Hussin, 2011; Baggetun and Wasson, 2006; Bhattacharya \& Chauhan, 2010; Bakar, 2009; Godwin-Jones, 2003; Warlick, 2005), and to be motivated (Amir, et al., 2011; Bakar \& Ismail, 2009), as well as to develop learner confidence (Bakar, 2009; Bakar, Latif, \& Ya’acob, 2010). It allows students to focus more on meaning than on form and "increases student interest, motivation and confidence in writing” (Noytim, 2010, p. 1131) and therefore holds great potential for L2 learning (Warschauer, 2010).

Most of the previous studies on the use of blogs in L2 learning to date are focused on the impact of interactions on language learning (e.g., Bakar, 2009), linguistic characteristics of feedback in L2 writing (Wang, 2009), facilitation of peer feedback through blogs (Dippold, 2009), development of language competence (Lee, 2010) and intercultural competence (Elola \& Oskoz, 2008), as well as pedagogical roles of blogs (Murray \& Hourigan, 2008) and pedagogical effectiveness (Freeman \& Brett, 2012). Although numerous studies have demonstrated that blogging can give rise to motivation (Hsu \& Wang, 2010; Lee, 2010; Sun, 2009) and collaboration (Freeman \& Brett, 2012; Godwin-Jones, 2003), few studies have ever centred on whether blog-mediated peer feedback in L2 writing can make any impact on these attitudinal constructs.

The aim of this study was to investigate the pedagogical affordances of readily available social blogs for L2 collaborative writing and to explore the innovative ways of integrating the Web 2.0 technology into the L2 writing curriculum. This was attempted to be achieved through an investigation of how blog-mediated peer feedback relates to learners' perceptions about their experience in an L2 writing course.

\section{Theoretical framework}

\section{Peer feedback and L2 writing}

Peer feedback in L2 writing refers to information provided by peers to inform, influence, or modify their partners' cognition and/or writing practices, which is intended to aid in enhancing their peers' performance in writing. It is used interchangeably with peer review, peer evaluation, and peer assessments (Gielen, Peeters, Dochy, Onghena, \& Struyven, 2010; Wasson \& Vold, in press) and thus can be regarded as a salient feature of part of the formative assessment approach (Gielen, et al., 2010) and part of the process writing approach (Jacobs, Curtis, Braine, \& Wang, 1998). Peer feedback is one of the components of social constructive learning (Vygotsky, 1962, 1978) of writing, which manifests itself in collaboratively providing and responding to peers' written comments or feedback. It offers L2 learners an opportunity to use target language in a meaningful way (Krashen, 1982), foster audience awareness (Zamel, 1982), develop writer confidence (Leki, 1990), and engage in negotiation of meaning and interaction (De Guerrero \& Villamil, 2000; Mendonca \& Johnson, 1994). Therefore through peer feedback students learn from each other and grow together in the journey of their L2 learning.

A cohort of studies show that peer feedback can contribute to L2 writing development. For instance Tsui and Ng's (2000) study showed that peer feedback could enhance a sense of audience, raise an awareness 
of the problems of their own writing, encourage collaborative learning in terms of learning from each other and gaining mutual support, as well as foster a sense of ownership of what they have written. It allows learners to reflect on the quality of their writing from the perspective of their peers (Paulus, 1999). When students offer feedback on their peers' writing it also gives feedback providers an opportunity to critically self-evaluate their own writing, which helps improve the writing of their own (Lundstrom \& Baker, 2009). Yang, Badger and Yu's (2006) comparative study of teacher and peer feedback in a Chinese, English as a foreign language (EFL) writing class reveals that peer feedback can give rise to the improvement of writing at the meaning level while teacher feedback at the form level. Also their study shows that peer feedback is more successful in bringing about more effective revisions than teacher feedback due to the fact that the former involves more of negotiation of meaning between peers, which can lead to enhancement of L2 learning (Doughty \& Long, 2003).

\section{Learner attitudes and L2 acquisition}

L2 learners have diverse attitudes towards issues related to the learning of an L2 language (Ellis, 1994). Their attitudes can have impact on the language proficiency level that they intend to achieve (Gardner, Moorcroft, \& Metforda, 1989). Learners with positive attitudes are more likely to achieve better success than those with negative attitudes towards the learning of the L2 language (Dörnyei, 1994; Feenstra, 1967; Gardner, 1960; Gardner \& Lambert, 1959; Lambert, Gardner, Olton, \& Tunstall, 1968; Svanes, 1988). When their attitudes are positive, they are more inclined to become motivated to learn the language and accordingly more willing to dedicate more time and effort to the learning endeavor (Culhane, 2004; Gardner, 1968; Gardner, Masgoret, \& Tremblay, 1999), as well as more behaviourally, cognitively, and affectively engaged in learning the L2 (Gardner, 2007).

For example, in their comparative study, Scott, Bell, and McCallum (2009) found that students who were less positive about L2 learning performed more poorly than those who were more positive even though both groups of the students wanted to learn the target language well. The reason is that attitudes can indirectly affect language performance through motivation (Gardner, Lalonde, Moorcroft, \& Evers, 1987). This has been considered one of the potent factors in L2 learning (Dixon et al., 2012; Gardner, 1968; Lambert, Gardner, Olton, \& Tunstall, 1968).

\section{Research questions}

The purpose of this study is twofold. First, the study attempts to examine whether blog-mediated peer feedback can enhance learners' L2 writing experience. Second, it is intended to explore the pedagogical challenges of integrating freely available blogs into the L2 writing curriculum. Specifically, the following three questions are addressed to guide this inquiry:

1. Does blog-mediated peer feedback relate to learners' motivation, collaboration, and course satisfaction?

2. Is such feedback a pedagogical enabler of an enhanced $L 2$ writing experience?

3. What are the pedagogical challenges of blog-mediated collaborative L2 writing?

\section{Methodology}

\section{Participants}

Participants ( $\mathrm{n}=40)$ were sophomore students of English majors from an intact L2 writing class in the same school at a university located in a metropolitan city in North China. They took a semester-long writing course on a weekly basis. As the course enrollment was dependent upon students' voluntary selection according to the university's instructional policies, the participants were not familiar with each other in this writing class when they met each other initially. Their initial in-class collaboration demonstrated that they were not active and remained less collaborative. At the time of data collection, two of them were absent from the class session, and two others failed to provide complete information in the questionnaire survey. As a result, the quantitative data for analysis only included the data valid from the 
36 participants. Their ages ranged from 18 to 20 years old (mean=19.28, SD=.566).

It has been a common phenomenon that female students outnumber their male counterparts in L2 classes in China. This was also true of this study. There were more female participants $(n=30)$, accounting for $83.3 \%$ of the total, than their male counterparts $(n=6)$, making up $16.7 \%$. They were taught by the same instructor researcher in the required English writing course to learn about the fundamentals of essay writing in a traditional classroom environment once a week. Beyond the class sessions, they performed blog-mediated collaborative writing tasks in small groups.

\section{Instruments}

Questionnaire

The questionnaire was adapted from dozens of other studies with five thematic constructs: feedback (Strijbos, Narciss, \& Dünnebier, 2010), motivation (Nie \& Lau, 2010), collaboration (Stump, Hilperta, Husman, Chung, \& Kim, 2011), and course satisfaction (Lee, Srinivasan, Trail, Lewis, \& Lopez, 2011). All of the constructs were measured through the use of 5-point Likert-type scales (1=completely disagree; $5=$ completely agree). The internal consistency for all dimensions of the constructs in the questionnaire was fairly good (Cronbach's Alpha=.874). The questionnaire fell into two parts: Part I was intended to collect quantitative data and Part II took an open-ended form, which aimed at collecting qualitative data. A sample of the constructs in Part I is given as follows:

Feedback (perceived adequacy of feedback)

Fairness

- I would be satisfied with this feedback.

- I would consider this feedback fair.

- I would consider this feedback justified.

Usefulness

- I would consider this feedback useful.

- I would consider this feedback helpful.

- This feedback would provide me a lot of support.

Acceptance

- I would accept this feedback.

- I would dispute this feedback.

- I would reject this feedback.

\section{Motivation}

Self-efficacy

- I am sure I can learn the skills taught in WRITING class well.

- I can do the hardest work in my WRITING class if I try.

- I can do almost all the work in WRITING class if I do not give up.

- If I have enough time, I can do a good job in all my WRITING work.

- Even if the work in WRITING is hard, I can learn it.

Task value scale

- I think learning WRITING is important.

- I find WRITING interesting.

- What I learn in WRITING is useful.

- $\quad$ Compared to other subjects, WRITING is useful.

\section{Collaboration}

- My peers and I actively work together to complete writing assignments.

- My group members and I actively work together to help each other understand the writing task.

- I get helpful comments about my part of the work from other members of the group.

- My peers and I actively work together to learn new things about the writing task.

- My peers and I actively share ideas about the writing task. 


\section{Course satisfaction}

- I felt I achieved the objectives in this course.

- I liked the course format (blog-based).

- I would recommend this course to others.

A sample of Part II was shown as follows:

- $\quad$ Does peer feedback motivate you to do the writing task? Why or why not?

- Does peer feedback motivate you to learn writing? Why or why not?

- Does peer feedback enhance collaboration with your peers? Why or why not?

- Does peer feedback push you to fully engage in learning essay writing? Why or why not?

- Does peer feedback help you to learn more about how to more effectively write an essay? Why or why not?

- Are there any benefits of peer feedback for improving your writing? If yes, what are they? If no, why not?

Semi-structured interviews

Two separate independent semi-structured focus interviews were conducted to make an in-depth exploration of what was going on in the course of the participants' performance of the writing tasks, behind the numbers revealed from the quantitative data. Semi-structured interviews make it possible for "the interviewer to begin with an established set of questions but also to deviate from those questions in order to probe more thoroughly into helpful and interesting responses” (Grady, 1998, p. 20).

According to Crowther and Lancaster (2009), "[f]ocus groups are particularly useful for exploring attitudes, perceptions and feelings about a topic" (p. 149). The participants were interviewed in such a fashion so as to enable the researcher to be more flexible to have the questions centered around "pre-determined issues and topics, but not in a rigid manner or necessarily in a rigid manner" (Crowther \& Lancaster, 2009, p. 147). Interviewing the participants in such a fashion also allows the researcher to address the issues or areas "that appear promising from the point of view of providing rich data and/or additional insights” (Crowther \& Lancaster, 2009, p. 147).

The participants interviewed were randomly chosen from the intact class, and there were four or five participants in each interview. The number of the interviews was determined by whether additional interviewees could cast more light on the research questions. In other words, the interviews were terminated after a second group of participants consistently gave similar responses.

The interview questions centered on the research problem, which concerned the relationship of blog-mediated peer feedback with the five constructs covered in the questionnaire survey. An example question set was: "Does peer feedback have any impact on your motivation to complete the writing task? If it does, how? If it doesn't, why not?”

\section{Artifacts}

Data also included the participants' artifacts or completed written assignments on their blogs. The artifacts included completed drafts of the essays and feedback on the revisions of their peers' drafts. Such data were used to identify the participants' immediacy of peer collaboration in terms of timeliness of responding to their peers' completed written assignments. In addition, they were used to identify the types of feedback and the effectiveness of blog-mediated collaboration in helping their peers' to improve their writing.

\section{Data collection}

The participants were divided into groups of three or four to participate in inside-of-class activities and to complete outside-of-class essay writing assignments via freely available blogs. They were recommended by the instructor researcher to register on sina.com, which boasts of the largest user population in China 
and many dignitaries and businesses as well as educational institutions make their online presence for publicity or promotional purposes. They were later informed of one another's blog addresses in the same group so that they could locate their peers' essays and provide feedback on them.

The participants performed two blog-mediated writing tasks in the course of the lecture period. One was a one-paragraph essay titled "The most important reason to love UIBE", and the other a five-paragraph essay titled "Is copycat economy a good thing for China?" The number of the words in each essay was restricted respectively. They were given the topic of the first task on the fifth week of the semester after they were taught the fundamentals of one-paragraph essay writing. Before the participants embarked on the tasks, they were notified of the guidelines for giving feedback as follows:

Read your peers' essays carefully and give feedback on them from the following perspectives based on what you have learned in class:

1. Topic sentence

2. Support details

3. Reworded sentence

4. Unity

5. Coherence

6. Organization

7. Mechanics (Grammar, spelling, word use, punctuation, capitalization, formatting, etc.)

They were required to submit the first draft of the essay by posting it on their own blog by a deadline within a week-long period. Also, they were required to respond to their peers' drafts by offering feedback on the drafts through their peers' blogs as soon as they could, and the peers who received feedback were expected to respond to the feedback providers as soon as they could. Then the participants were required to make corrections based on their peer feedback as well as the instructor's feedback, which was given to each participant after the group had completed the requirements. Finally the instructor made comments on some of the participants' better essays and the effective feedback provided by some of the participants in part of a class session. Such comments were intended to guide the students to critically read their peers' essays and provide effective feedback.

In the course of the one-paragraph essay writing, providing feedback, and making corrections, the participants were taught how to write a five-paragraph essay in class. After the module for five-paragraph essay writing was completed, the students were required to complete a five-paragraph essay with the same requirements for the one-paragraph essay writing task, namely submitting the essay by posting it on their own blog and providing feedback on their peers' essays on their peers' blogs and making corrections on their own blog as soon as they could based on the following feedback guidelines while the teaching of longer essays was under way in class:

Please read your peers' essays carefully and give feedback on them from the following perspectives (adapted from Bailey \& Powell, 2008) based on what you have learned in class:

1. Introduction
A. Motivator
B. Thesis statement
C. Blue print

2. Body

A. First central paragraph

1) Topic sentence

2) Support details

B. Second central paragraph

1) Topic sentence

2) Support details

C. Third central paragraph

1) Topic sentence

2) Support details 
3. Conclusion

A. Reworded thesis

B. Clincher

4. Unity

5. Coherence

6. Mechanics (Grammar, spelling, word use, punctuation, capitalization, formatting, etc.)

The instructor researcher then made comments on some of exemplary essays and peer feedback in a session and administered the questionnaire to the students at the end of the session, which was followed on the same day by two focus interviews.

\section{Data analysis}

There were two types of data in this study; quantitative and qualitative. The quantitative data were first analyzed by descriptive statistics (e.g., mean and SD) via PASW Statistics 18.0, which is a statistical analysis software application. Then the Pearson Product-Moment Correlation was run to determine the respective relationship of blog-mediated peer feedback with learners' motivation, collaboration, and course satisfaction.

The qualitative interview and open-ended questionnaire survey data were processed according to Zhang's (2013) study. The data were first classified into themes with the help of the NVivo 7 qualitative analysis software by segmenting and coding the text into categories that corresponded to the focus questions. The identified themes were utilised to be supplemented with the quantitative data in the analysis.

\section{Results and discussion}

\section{The participants' attitudinal perceptions of blog-mediated collaborative L2 writing}

Table 1 revealed that the participants had positive perceptions of the role of blogs in L2 writing. They believed that they were better motivated (mean $=4.174, \mathrm{SD}=.499$ ) and more collaborative (mean=3.661, $\mathrm{SD}=.701$ ) in the course of writing activities. Also they were satisfied with the course (mean=3.686, $\mathrm{SD}=.523$ ). The results showed that the mean scores of the participants' attitudinal perceptions were all well above the benchmark (mean=3), indicating that the teaching and learning of collaborative L2 writing via blogs was pedagogically intriguing and beneficial.

Table 1

Descriptive statistics of the selected variables (attitudinal perceptions)

\begin{tabular}{llllll}
\hline & $\mathrm{N}$ & Minimum & Maximum & Mean & Std. Deviation \\
\hline Motivation & 36 & 2.71 & 5.00 & 4.174 & .499 \\
Collaboration & 36 & 2.00 & 4.80 & 3.661 & .701 \\
Courses satisfaction & 36 & 2.33 & 4.67 & 3.686 & .523 \\
\hline
\end{tabular}

The findings of this study are in line with those of previous studies. First, blogging is motivating (mean=4.174, SD=.499) for L2 learners of writing (Amir, et al., 2011; Bakar \& Ismail, 2009; Hsu \& Wang, 2010; Lee, 2010; Sun, 2009). As Trajtemberg \& Yiakoumetti (2011) pointed out, “[b]logs assist in motivating learners to use language for real communicative purposes and to write in English in ways that they have not previously experienced" (p. 9). Also, blogging can enhance collaboration (Freeman \& Brett, 2012; Godwin-Jones, 2003) though outliers might have existed among the participants (mean=3.661, $\mathrm{SD}=.701$ ). Moreover, blogging can enable L2 learners to learn in an interactive manner (Ducate \& Lomicka, 2005; Miceli, et al., 2010). Such affordances of blogging were also recognized by the interviewees as follows:

Blogs are an open-ended platform, where people can read and comment on what I've written anytime and anywhere. I have to work hard on the writing task seriously and to produce better essays just because my peers in the same group and beyond may read my 
essays. Also, I have to complete my writing tasks as soon as I can so that I won't hinder the progress of collaborative writing as a group. (Carol, interview excerpts)

The teaching and learning of L2 writing with this technology is in effect an accommodation of life and learning styles of the students of the digital generation. They are comfortable with emerging technologies and expose themselves to these technologies, especially those related to social communication, largely on a somewhat regular basis. When pedagogical innovations in transforming learning and teaching with these technologies relate to their routine life, it is likely that they can embrace them in a self-driven manner. Obviously, the findings reveal that the integration of the blog technology can have enormous potential for transforming the teaching and learning L2 writing in terms of enhanced motivation, collaboration, and course satisfaction.

\section{The relationship of blog-mediated peer feedback with the participants' attitudinal perceptions}

Blog-mediated peer feedback is conducive to an enhanced L2 writing experience. According to the questionnaire survey, the participants held that blog-mediated peer feedback is significantly positively correlated with learner motivation $(\mathrm{r}=.450, \mathrm{p}<.01)$, collaboration $(\mathrm{r}=.561, \mathrm{p}<.01)$, and satisfaction with the writing course $(\mathrm{r}=.487, \mathrm{p}<.01)$ (See Table 2$)$.

Table 2

Correlations between perceived adequacy of blog-mediated peer feedback and targeted attitudinal variables

\begin{tabular}{lll}
\hline \multirow{2}{*}{ Attitudinal variables } & \multicolumn{2}{l}{ Peer feedback } \\
\cline { 2 - 3 } Motivation & Pearson Correlation & Sig. (2-tailed) \\
\cline { 2 - 3 } Collaboration & $.450^{* *}$ & .006 \\
Course satisfaction & $.561^{* *}$ & .000 \\
** Correlation is significant at the 0.01 level (2-tailed).
\end{tabular}

Peer feedback mediated through blogs is immediately available to bloggers, and can be accessed anytime and anywhere. Such immediacy motivated the learners to perform and complete their writing tasks as quickly as they could, to share their work with others. In the meantime they also expected their peers to offer feedback on their work in a similar fashion.

After finishing my work, I'm always eager to see others' comments on my blog. I do enjoy the collaboration. Sometimes, I feel that those comments are kinds of motivation for me to write something. (Sarah, open-ended questionnaire survey data)

Peer feedback is taken as evidence of attention from the intended readers. Such attention becomes sources of motivation. The participants tended to attract and maintain the attention of their peers by performing the tasks diligently.

If I have received feedback from my peers, I'll think that they have really read my essay. Knowing that, I'll have the motivation to write more and more, and I don't want to let me down. (Lisa, open-ended questionnaire survey data)

Moreover, protecting one's face is another source of motivation. The Chinese are obsessed with face. Protecting one's own face in a group setting has been critical for the people of this culture in all contexts. The same is true of the students in this collaborative writing scenario. As the feedback was displayed on blogs publicly, at least in this case, the participants were psychologically motivated and meta-cognitively aware of the role of the quality of their essays in the protection of their face. Posting their essays on blogs was perceived as displaying their face to the public. That is to say, their posted essays can lead to either loss of face or gain of face. Thus, to seek positive peer feedback becomes one of the ways to protect face. In order to achieve the goal, the participants had to work hard to write better essays so that they could best 
present themselves and receive positive peer feedback.

In order to convey a better impression of me among my peers and avoid losing face, I wanted to try my best to write in order to get positive feedback. (Julie, open-ended questionnaire survey data)

With regard to collaboration, blog-mediated peer feedback allows the peers to get acquainted with each other, to inform each other, and to accomplish the goal together. The feedback is viewed as a bridge that connects and cements the relationship of the peers. Such a form of collaboration enabled them to free themselves from spatial and temporal constraints, leading to favorable milieu for the learning of collaborative L2 writing.

Blog-mediated collaborative writing gives me an opportunity to know more of my classmates and allows me to enhance my participation in inside-of-class activities. I feel that I'm truly a member of the class. This is different from other classes, where I just want to get course credits without active participation. Learning writing in this class enhances my presence in class. (Sally, interview excerpts)

Giving feedback to each other's work makes me feel strongly that we are a group, and that we are working together to work out better essays. That feeling is awesome. (Victoria, open-ended questionnaire survey data)

The correlations between blog-mediated peer feedback and participants' satisfaction with this course are manifested by the dynamics of their collaboration and the blended nature of the course. In this writing course, the students collaborated with each other both inside of class in group discussions, and outside of class through feedback on their peers' written work. Specifically, when they were in class, they were involved in collaboration with each other as a group to solve writing problems with the writing skills they had learned. When they were outside of class, they were engaged in collaborative writing in terms of helping each other improve their essays through completing their writing tasks via their individual blogs and providing peer feedback via their peers' blogs. The blending of physical classroom-based learning of L2 writing in regular class sessions and blog-mediated interaction and collaboration outside of the sessions aids in enhancing the participants' motivation, collaboration, and course satisfaction.

When we completed the collaborative writing assignments, we (peers) could help each other through feedback. This enabled me to learn a lot from my peers, and I felt very delighted. With such mood, I was pretty enthusiastic about this writing course. (Susan, interview excerpts)

Although the students did not find it a new experience to write blogs, they did find it fun and pedagogically motivating and virtually more convenient to collaborate with each other with such a Web 2.0 technology integrated into the writing curriculum.

Collaborative writing via blogs is no longer simply completing a writing task and submitting the completed work. It allows my peers to find the shining points of my essay, which is motivating and helps me to develop my confidence. Also, it allows me to witness the process of my progress in writing. (Sarah, interview excerpts)

Also, as was found out by previous studies such as Yang (2009) and Makri \& Kynigos (2007), peer feedback encourages self-reflection on their work. To some extent, writing does not mean completing and submitting a draft in order to earn a score for a course credit, but it means more of a self-reflection process, during which L2 writers are made noticeable of their zone of proximal development defined by Foster and Ohta (2005) as "the distance between the actual development level as determined by individual linguistic production, and the level of potential development as determined through language produced collaboratively with a teacher or peer” (p. 144). 
We generally can’t identify the mistakes we have made in our writing. My peers' feedback gives me an opportunity of knowing where I'm wrong and why I'm wrong. That encourages my self-reflection of my writing. (Sally, interview excerpts)

To summarize, both the quantitative and qualitative data show that the participants have gained a rewarding experience of learning L2 writing when they are engaged in blog-mediated collaborative writing activities. They have become more motivated and collaborative due to the novel form of course delivery and the convenience afforded by the technology. Also peer feedback is regarded as being helpful to build friendship among peers, to complement with peers' writing skills, to encourage collaboration, to boost confidence in writing, and to facilitate critical self-reflection.

\section{Blog-mediated peer feedback and learners' L2 writing experience}

It is apparent that blog-mediated peer feedback has helped give rise to an enhanced learner experience of L2 writing in many ways. To begin with, such an experience originates from the free access to this blog service. Blogs provide an ideal platform for the teaching and learning of L2 writing, and they are made available to both instructional practitioners and students involved, free of any financial costs. As Chinese college students normally live in campus dormitories and are not provided with free access to international Internet services (Zhang, 2013), the blog service, which is hosted in mainland China, can relieve the students of financial difficulty in accessing the service. Therefore such availability enables them to harness the technology for a novel L2 learning experience.

Peer feedback makes the cognitive gap more noticeable. After students have completed their essays, they are incapable of identifying the mistakes that may have existed in their essay. Through feedback, they are informed of and able to notice the weaknesses of their essays and how they can improve them. Such noticing is essential to effective L2 acquisition, especially to the acquisition of L2 forms (Mackey, 2006).

Peer feedback provides a multidimensional perspective of essay writing. In L2 writing, peer feedback can not only make linguistic forms salient to feedback recipients but also broaden their perspectives in terms of how a particular problem can be effectively addressed. Such an affordance helps extend the breadth and depth of their writing, which can eventually give rise to the building of a community of experts.

In addition, peer feedback increases social presence. When the students are preparing their essays, they tend to think that their peers are waiting to read their essays while composing their own essays. After they have completed their essays and have had them posted on their blogs, they believe that their peers will show up on their blogs in terms of reading their essays and providing feedback on them. When students receive peer feedback, they tend to believe that their peers will be there, namely on their blogs, and respond to their essays with comments. Therefore, they tend to wait for their feedback and revise their essays based on the feedback they have received. Then they expect their peers to provide further feedback. Such interaction and social presence can give rise to a community of practice.

Furthermore, peer feedback leads to more attention directed to the instructor inside of class and to an enhanced quality of writing outside of class. Due to the fact that writing assignments are associated with course content, students have to be attentive in class if they are capable of offering relevant and constructive feedback or if they are able to make a critical and thorough evaluation of their peers' work. What's more, peer feedback, which is one of the ways to protect one's face, is a driving force of enabling learners to work diligently beyond lecture sessions. They work hard to yield a more impressive essay and to deliver a responsive and better-targeted support in terms of metalinguistic knowledge and writing skills covered in the lectures. With these endeavours, learners are able to make good use of both inside-of-class and outside-of-class time.

Finally, peer feedback is conducive to the establishment of an engaging milieu inside of class for the students. The students did not know each other at the time when they took the course. When they performed in-class activities, active interaction among the peers was absent in class. After they carried out blog-mediated collaborative writing activities via feedback, they got to know each other and established 
strong peer-to-peer relationships. Such relationships have exerted considerable impact on peer engagement in in-class activities and become an enabler of working collaboratively with their peers inside of class in a proactive fashion.

In summary, blog-mediated peer feedback contributes to social presence and confidence building and gives rise to the creation of the zone of proximal development. Such affordances can help peer learners to have an enjoyable and fruitful experience.

\section{Pedagogical challenges of collaborative L2 writing via freely available social blogs}

Even though blog services are freely available, it does not mean that they can be used effectively for the teaching and learning of L2 writing without taking the challenges into consideration. In effect, there are a number of pedagogical challenges that need to be addressed head-on before learning effectiveness can take place.

First, the choice of blog services is critical. Some of the blogs are more technically reliable and suitable for such an educational endeavor than others. As stated, college students in China normally live on campus and they do not have free access to international Internet services. Ideally, it may still be better to utilise free blog services that are provided by blog providers in English-speaking countries, as the blog interface is designed in the target language, and the students may feel more comfortable with it. However, the access to those blogs could be problematic for a large majority, if not all, of the students unless they are willing to purchase the Internet access service at their own expense or at the expenses of the institutions where they study. Therefore choosing a blog that is accessible to all in whatever way should be the chosen strategy. Some of the blog services require registration before users can make comments on others' blog posts. This could be troublesome due to the fact that users have to remember dozens of blog addresses as well as usernames and passwords, otherwise access to the blogs could become impossible. Moreover, posts may be deleted on some blogs by blog administrators indiscriminately and without providing a reason. Some blogs may impose severe restriction on politically sensitive words; as is the case in China. After students have posted their written work on their blogs, unknown to them, their posts may be deleted by a blog administrator due to the fact that their blogs may have contained words under censorship. Such deletion is very discouraging for the unfortunate students because it can disrupt the collaborative process of a group when their peers fail to locate their essays and are unable to provide feedback. In the meantime, the students also feel frustrated when some of the words are blocked from being posted. Therefore all of these technical issues, not excluding others, need to be addressed well before pedagogical strategies are considered.

Second, maintaining the effectiveness of peer feedback matters. Peers are not teachers, and it is the teachers who are more capable of knowing how to help students become better writers (Carson \& Nelson, 1996; Nelson \& Carson, 1998; Yang et al., 2006). However, that does not mean that L2 learners of writing are unable to benefit from peer feedback at all. When the requirements of blog-mediated writing tasks are less specific and explicit, peer feedback may take many forms. Consequently some peers may offer constructive feedback on the weaknesses of their peers' essays while others may miss the target altogether. In order to enhance feedback effectiveness, the instructor needs to make it clear to the students what is expected to be achieved at the end of a collaborative learning activity. An optimal strategy is that the students are provided with a feedback outline, coupled with an example, demonstrating what effective feedback is and how that can be done effectively in a brief session at the outset. In so doing, effective peer feedback can be largely ensured.

Finally, teacher workload is a growing concern. After the students have collaboratively worked on an essay via blogs, they expect comments from their peers. Meanwhile, as the interviewees revealed, they also expect the teacher's attention to what they have produced. This suggests that the teacher may have to maintain constant attention to how well the students have been progressing in the course of the students' blog-mediated writing activities in terms of the essay completed, peer feedback, and revision. In this way the students may become more motivated and engaged. However due to an increasing workload of teaching and research, it is particularly challenging for the instructor, who is already burdened with 
routine obligations, to perform other duties beyond his or her regular work schedule.

\section{Pedagogical implications}

The integration of blogs into the L2 writing curriculum allows learners to perform collaborative and interactive writing tasks in a responsible and mutually beneficial way. It affords unparalleled opportunities for the learners to continue their journey of writing learning beyond the physical boundaries of time and space. Also it is likely to lead to a pedagogical transformation of the teaching and learning of L2 writing. The findings of this study can offer both theoretical and practical implications.

Theoretically, this study contributes to future understanding of the role of noticing in L2 acquisition. Noticing is an important construct in L2 acquisition and plays an essential role in the acquisition of metalinguistic knowledge (Truscott, 1998). As learners are unable to identify their own mistakes in L2 writing tasks, feedback can enable linguistic forms to be explicit and salient to the feedback recipients. As a result, they can notice and anchor what their mistakes are and have a better sense of how to improve their writing with their peers' scaffolding support. Moreover the role of noticing may not be only limited to the acquisition of metalinguistic knowledge. Just as is evidenced by the findings of this study, noticing can also give rise to learners' broader perspectives of thinking and enhanced levels of organisation in an essay, such as thesis statement, body, and conclusion as well as unity and coherence, among many other nonlinguistic elements. Thus learners are able to put themselves on the path to improved language skills after they have sufficient collaborative writing practice.

Practically, the teaching and learning of L2 writing may go beyond the traditional classroom environments. Students of the digital generation grow up in a world of technology and learn differently from the learners of the 1990s, not to mention those of older generations. They are constantly engaging themselves in technology-rich reading, writing, and critical thinking. In language education, technology needs to be integrated throughout a routine curriculum to accommodate their needs and habits of learning so as to maximize the effectiveness of target language learning. In the teaching and learning of L2 writing, a blended approach may be adopted to bring about a pedagogical paradigm shift. An optimal pedagogy of teaching L2 writing may involve a blending of teaching both in a classroom-based setting and in a technology-enhanced environment. More specifically, the classroom-based teaching may centre on the lecturing of writing basics while the technology-enhanced teaching such as blog-mediated learning of L2 writing is taken as an extension of classroom-based teaching. For example, students can be placed in groups of three or four people. The number of the group members should not exceed four people, otherwise they may feel more stressed about their workload. Then they are asked to carry out group collaborative writing projects via blogs in terms of writing essays of their own, giving feedback to peers' essays, revising essays based on peer feedback, and self-reflecting on the differences between the original draft and the final draft. In the course of the activities, the instructor may monitor and facilitate the students' collaborative process, strengthening a community of practice via feedback as well as pedagogical comments and technical support.

\section{Conclusions}

The findings of this study reveal that blog-mediated peer feedback can give rise to an enhanced L2 writing experience. It enables L2 learners to be more motivated and collaborative in the process of completing writing tasks. In addition, it enhances learner satisfaction with the effectiveness of a writing course. These findings are in line with those of the studies conducted by Hsu \& Wang (2010), Lee (2010), Sun (2009) as well as Freeman \& Brett (2012) and Godwin-Jones (2003), highlighting the role of peer feedback in facilitating L2 acquisition. The findings also demonstrate that the effectiveness of integrating this socially popular technology into the L2 writing curriculum is dependent upon two major factors. One is that a pedagogical paradigm shift should be made from classroom-based lecturing to a blended approach to the teaching of L2 writing; the other is that pedagogical challenges need to be addressed. The study concludes that group collaborative writing via blogging can not only encourage collaboration and self-reflection but also engage learners in noticing and peer co-construction of knowledge. 
In anchoring the findings of this study in the larger literature, its limitations must be acknowledged; some of which may offer opportunities for future research. First, this study is longitudinal in nature, and a dynamic, holistic view of the effect of blog-mediated peer feedback may not have been well presented. Future studies may use a mixed research methods approach and a phenomenographic perspective in order to "[enable] us to observe any changes in variables which may occur over time" (Rasinger, 2010, p. 57). Second, the time span of the L2 writing course covered in this study is relatively short. As the time span varies, learners' perceptions of blog-mediated learning may change accordingly. Future studies may extend the time span so as to enable researchers to collect richer data sets. Such an effort will help paint a fuller picture of the role of blogging in the learning of L2 writing. Finally, the effectiveness of blog-mediated peer feedback in L2 writing needs to be addressed empirically. Although peer feedback has been identified to be positively correlated to motivation, collaboration, and course satisfaction in this study, its correlation to writing performance still remains little known. Future studies may be conducted toward an examination of how blog-mediated peer feedback has made impact on L2 learners' writing performance in a quantitative comparative research design.

\section{Acknowledgements}

We would like to extend our gratitude to the two AJET anonymous reviewers for their insightful and constructive comments on this paper. This study has been partially funded by the Fundamental Research Funds for the Central Universities and the Research Funds of Renmin University of China (No. 12XNK001) and by the Institute for Applied Linguistics at the University of International Business and Economics, Beijing, China.

\section{References}

Amir, Z., Ismail, K., \& Hussin, S. (2011). Blogs in language learning: Maximizing students' collaborative writing. Procedia Social and Behavioral Sciences, 18, 537-543.

Baggetun, R., \& Wasson, B. (2006). Self-regulated learning and open writing. European Journal of Education, 41(3-4), 453-72.

Bailey, E. P., \& Powell, P. A. (2008). The practical writer (9th ed.). Boston: Thomson/Wadsworth.

Bakar, N. A. (2009). E-learning environment: blogging as a platform for language learning. European Journal of Social Sciences, 9(4), 594-604.

Bakar, N. A., Ismail, K. (2009). Using blogs to encourage ESL students to write constructively in English. Journal of Teaching and Learning in Higher Education, 1(1). 45-57.

Bakar, N. A., Latif, H., \& Ya'acob, A. (2010). ESL Students feedback on the use of blogs for language learning. 3L: The Southeast Asian Journal of English Language Studies, 16(1), 120-141.

Bhattacharya, A., \& Chauhan, K. (2010). Augmenting learner autonomy through blogging. ELT Journal, 64(4), 376-384. doi: 10.1093/elt/ccq002

Brescia, W. F., \& Miller, M. T. (2006). What's it worth? The perceived benefits of instructional logging. Electronic Journal for the Integration of Technology in Education, 5, 44-52.

Carson, J. G., \& Nelson, G. L. (1996). Chinese students' perceptions of ESL peer response group interaction. Journal of Second Language Writing, 5(1), 1-19.

Chu, S. K. W., Chan, C. K. K., Tiwari, A. F. Y. (2012). Using blogs to support learning during internship. Computers \& Education, 58(3), 989-1000.

Churchill, D. (2009). Educational applications of Web 2.0: Using blogs to support teaching and learning. British Journal of Educational Technology, 40(1), 179-183.

Crowther, D, \& Lancaster, G. (2009). Research methods: A concise introduction to research in management and business consultancy (2nd ed.). Oxford, UK: Elsvier.

Culhane, S. F. (2004). An intercultural interaction model: Acculturation attitudes in second language acquisition. Electronic Journal of Foreign Language Teaching, 1(1), 50-61.

De Guerrero, M. C. M., \& Villamil, O. S. (2000). Activating the ZPD: Mutual scaffolding in L2 peer revision. Modern Language Journal, 84(1), 51-68.

Dippold, D. (2009). Peer feedback through blogs: Student and teacher perceptions in an advanced German class. ReCALL, 21(01), 18-36.

Dixon, L. Q., Zhao, J., Shin, J.-Y., Wu, S., Su, J.-H., Burgess-Brigham, B., ... Snow, C. (2012). What we 
know about second language acquisition: A synthesis from four perspectives. Review of Educational Research March, 82(1), 5-60.

Dörnyei, Z. (1994). Motivation and motivating in the foreign language classroom. Modern Language Journal, 78(3), 273-284.

Doughty, C. J., \& Long, M. H. (Eds.) (2003). The handbook of second language research. Oxford: Blackwell Publishing.

Ducate, L. C., \& Lomicka, L. L. (2005). Exploring the blogosphere use of web logs in the foreign language classroom. Foreign Language Annals, 38(3), 410-421.

Ellis, R. (1994). The study of second language acquisition. Oxford: Oxford University Press.

Ellison, N. B., \& Wu, Y. (2008). Blogging in the classroom: A preliminary exploration of student attitudes and impact on comprehension. Journal of Educational Multimedia and Hypermedia, 17(1), 99-122.

Elola, I., \& Oskoz, A. (2008). Blogging: Fostering intercultural competence development in foreign language and study abroad contexts. Foreign Language Annals, 41(3), 454-477.

Feenstra, H. J. (1967). Aptitude, attitude and motivation in second language acquisition. Unpublished Ph.D. dissertation, University of Western Ontario.

Foster, P., \& Ohta, A. S. (2005). Negotiation of meaning and peer assistance in second language classroom. Applied Linguistics, 26(3), 402-430.

Freeman, W., \& Brett, C. (2012). Prompting authentic blogging practice in an online graduate course. Computers \& Education, 59(3), 1032-1041. doi: 10.1016/j.compedu.2012.03.019.

Gardner, R. C. (1960). Motivational variables in second-language acquisition. Unpublished doctoral dissertation, McGill University, Montreal, Quebec, Canada.

Gardner, R. C. (1968). Attitudes and motivation: Their role in second-language acquisition. TESOL Quarterly, 2(3), 141-150.

Gardner, R. C. (2007). Motivation and second language acquisition. Porta Linguarum, 8, 9-20.

Gardner, R. C., Lalonde, R. N., Moorcroft, R., \& Evers, F. T. (1987). Second language attrition: The role of motivation and use. Journal of Language and Social Psychology, 6(1), 29-47.

Gardner, R. C., \& Lambert, W. E. (1959). Motivational variables in second-language acquisition. Canadian Journal of Psychology, 13, 266-272.

Gardner, R. C., Masgoret, A.-M., \& Tremblay, P. F. (1999). Home background characteristics and second language learning. Journal of Language and Social Psychology, 18(4), 419-437.

Gardner, R. C., Moorcroft, R., \& Metforda, J. (1989). Second language learning in an immersion programme: Factors influencing acquisition and retention. Journal of Language and Social Psychology, 8(5), 287-305.

Gielen, S., Peeters, E., Dochy, F., Onghena, P., \& Struyven, K. (2010). Improving the effectiveness of peer feedback for learning. Learning and Instruction, 20(4), 304-315.

Glogoff, S. (2007). Blogging in an online course: A report on student satisfaction among first-time bloggers. In G. Richards (Ed.). In Proceedings of World Conference on E-Learning in Corporate, Government, Healthcare, and Higher Education 2003 (pp. 2160-2162). Chesapeake, VA: AACE.

Godwin-Jones, R. (2003). Emerging technologies - blogs and wikis: Environments for online collaboration. Language Learning \& Technology, 7(2), 12-16.

Grady, M. P. (1998). Qualitative and action research: A practitioner handbook. Bloomington, IN: Phi Delta Kappa Educational Foundation.

Halic, O., Lee, D., Paulus, T., \& Spence, M. (2010). To blog or not to blog: Student perceptions of blog effectiveness for learning in a college-level course. Internet and Higher Education, 13(4), 206-213.

Hsu, H.-Y., \& Wang, S. (2010). The impact of using blogs on college students' reading comprehension and learning motivation. Literacy Research and Instruction, 50(1), 68-88. doi: 10.1080/19388070903509177

Huck, S. W. (2007). Reform in statistical education. Psychology in the Schools, 44(5), 527-533.

Jacobs, G. M., Curtis, A., Braine, G., \& Wang, S-Y. (1998). Feedback on student writing: taking the middle path. Journal of Second Language Writing, 7(3), 307-317.

Kang, I., Bonk, C. J., \& Kim, M-C. (2011). A case study of blog-based learning in Korea: Technology becomes pedagogy. Internet and Higher Education 14(4), 227-235.

Kim, H. N. (2008). The phenomenon of blogs and theoretical model of blog use in educational contexts. Computers \& Education, 51(3), 1342-1352.

Korea Internet \& Security Agency. (2012). 2011 Survey on the Internet usage executive summary. 
Retrieved from http://isis.kisa.or.kr/eng/board/fileDown.jsp?pageId=040100\&bbsId=10\&itemId=317\&athSeq=1

Krashen, S. (1982). Principles and practice in second language learning and acquisition. Oxford: Pergamon.

Lambert, W. E, Gardner, R. C, Olton, R., \& Tunstall, K. (1968). A study of the roles of attitudes and motivation in second language learning. In J. Fishman (Ed.), Readings in the sociology of language (pp. 473-491). Paris: Mouton-The Hague.

Lee, L. (2010). Fostering reflective writing and interactive exchange through blogging in an advanced language course. ReCALL, 22(2), 212-227.

Lee, S. J., Srinivasan, S., Trail, T., Lewis, D., \& Lopez, S. (2011). Examining the relationship among student perception of support, course satisfaction, and learning outcomes in online learning. Internet and Higher Education 14(3), 158-163.

Leki, I. (1990). Potential problems with peer responding in ESL writing classes. CATESOL Journal, 3, 5-17.

Lundstrom, K., \& Baker, W. (2009). To give is better than to receive: The benefits of peer review to the reviewer's own writing. Journal of Second Language Writing 18(1) 30-43.

Mackey, A. (2006). Feedback, noticing and instructed second language learning. Applied Linguistics, 27(3), 405-430.

Makri, K., \& Kynigos, C. (2007). The role of blogs in studying the discourse and social practices of mathematics teachers. Educational Technology \& Society, 10(1), 73-84.

Mendonca, C. O., \& Johnson, K. E. (1994). Peer review negotiations: Revision activities in ESL writing instruction. TESOL Quarterly, 28(4), 745-769.

Miceli, T., Murray, S. V., \& Kennedy, C. (2010). Using an L2 blog to enhance learners' participation and sense of community. Computer Assisted Language Learning, 23(4), 321-341.

Murray, L., \& Hourigan, T. (2008).Blogs for specific purposes: Expressivist or socio-cognitivist approach? ReCALL, 20(1), 82-97.

Nelson, G., \& Carson, J. (1998). ESL students’ perceptions of effectiveness in peer response groups. Journal of Second Language Writing, 7(2), 113-131.

NetEase Tech. (2012, January 11). An overview of China’s Internet industry in 2011. Retrieved from http://tech.163.com/12/0111/14/7NGC3BA700094MA3.html

Nie, Y., \& Lau, S. (2010). Differential relations of constructivist and didactic instruction to students' cognition, motivation, and achievement. Learning and Instruction, 20(5), 411-423.

Noytim, U. (2010). Weblogs enhancing EFL students' English language learning. Procedia - Social and Behavioral Sciences, 2(2), 1127-1132.

Paulus, T. M. (1999). The effect of peer and teacher feedback on student writing. Journal of Second Language Writing, 8(3), 265-289.

Rasinger, S. M. (2010). Quantitative methods: Concepts, frameworks and issues. In L. Litosseliti (Ed.), Research methods in linguistics (pp. 49-67). London: Continuum International.

Reese, S. (2011). Quick stat: Three in four US households will be online next year. Retrieved from http://www.emarketer.com/blog/index.php/tag/number-of-internet-users/

Robertson, J. (2011). The educational affordances of blogs for self-directed learning. Computers \& Education, 57(2), 1628-1644.

Scott, K. W., Bell, S. M., \& McCallum, R. S. (2009). Native language reading and spelling abilities and attitudes toward learning a second language. Preventing School Failure, 54(1), 30-40.

Strijbos, J., Narciss. S., \& Dünnebier, K. (2010). Peer feedback content and sender’s competence level in academic writing revision tasks: Are they critical for feedback perceptions and efficiency? Learning and Instruction, 20(4), 291-303.

Stump, G. S., Hilperta, J. C., Husman, J., Chung, W., \& Kim, W. (2011). Collaborative learning in engineering students: gender and achievement. Journal of Engineering Education, 100(3), 475-497.

Sun, Y.-C. (2009). Voice blog: An exploratory study of language learning. Language Learning \& Technology, 13(2), 88-103.

Svanes, B. (1988). Attitudes and 'cultural distance' in second language acquisition. Applied Linguistics, 9(4), 357-371.

Tencent IT. (2012). Chapter four of the 29th CNNIC report: The status quo of the Internet use by Chinese netizens. Retrieved from http:/tech.qq.com/a/20120116/000277.htm 
Top, E. (2012). Blogging as a social medium in undergraduate courses: Sense of community best predictor of perceived learning. The Internet and Higher Education, 15(1), 24-28.

Trajtemberg, C., \& Yiakoumetti, A. (2011). Weblogs: A tool for EFL interaction, expression, and self-evaluation. ELT Journal, 65(4), 437-445.

Truscott, J. (1998). Noticing in second language acquisition: a critical review. Second Language Research, 14(2), 103-135.

Tsui, A. B. M., \& Ng, M. (2000). Do secondary L2 writers benefit from peer comments? Journal of Second Language Writing, 9(2), 147-170.

Vygotsky, L. (1962). Thought and language. Cambridge, MA: MIT Press.

Vygotsky, L. (1978). Mind in society: The development of higher psychological processes. Cambridge, MA: Harvard University Press.

Wang, H.-C., (2009). Weblog-mediated peer editing and some pedagogical recommendations: A case study. The JALT CALL Journal, 5(2), 29-44.

Warlick, D. (2005). Classroom blogging: A teacher's guide to the blogosphere. Raleigh: Lulu Press.

Warschauer, M. (2010). Invited commentary: New tools for teaching writing. Language Learning \& Technology, 14(1), 2-8.

Wasson, B., \& Vold, V. (in press). Leveraging new media skills in a peer feedback tool. Internet and Higher Education. doi:10.1016/j.iheduc.2011.10.002

Williams, J. B., \& Jacobs, J. (2004). Exploring the use of blogs as learning spaces in the higher education sector. Australasian Journal of Educational Technology, 20(2), 232-247.

Yang, M., Badger, R., \& Yu, Z. (2006). A comparative study of peer and teacher feedback in a Chinese EFL writing class. Journal of Second Language Writing, 15(3), 179-200.

Yang, S. H. (2009). Using blogs to enhance critical reflection and community of practice. Educational Technology \& Society, 12(2), 11-21.

Zamel, V. (1982). Writing: The process of discovering meaning. TESOL Quarterly, 16(2), 195-209.

Zhang, H. (2013). Pedagogical challenges of spoken English learning in the Second Life virtual world: A case study. British Journal of Educational Technology, 44(2), 243-254.

Corresponding author: Wei Song, wsong@ruc.edu.cn

Australasian Journal of Educational Technology @ 2014.

Please cite as: Zhang, H., Song, W., Shen, S., \& Huang, R. (2014). The effects of blog-mediated peer feedback on learners' motivation, collaboration, and course satisfaction in a second language writing course. Australasian Journal of Educational Technology, 30(6), 670-685. 